\title{
The 2017 International Workshop on Statistical Genetic Methods for Human Complex Traits (Formerly the 'Methodology of Twin and Family Studies Advanced Workshop'): March 6th-March 10th, 2017
}

The next workshop will be held in Boulder, Colorado, March 6-10th, 2017, with John Hewitt as local host, and Dr. Benjamin Neale, Broad Institute and Massachusetts General Hospital, and Prof. David Evans, Diamantina Institute, University of Queensland, as co-directors. This advanced course is intended for those who are already familiar with the statistical and genetic principles for studying human complex traits and have some familiarity with programming in $R$. The course will focus on statistical methods for analyzing genome-wide association studies (GWAS) and genome sequence data. Hands-on analysis will be an integral part of the course and will employ networked notebook computers. A provisional schedule will be posted at https://ibg.colorado.edu/dokuwiki/doku. php?id=workshop:2017:schedule.

The registration fee is $\$ 550$, payable by January 27 , 2017. Thereafter, the fee will be $\$ 650$. Non-payment by February 17, 2017, will result in your registration being dropped, and cancellations after that date will be non-refundable. Refunds of payments will incur a $\$ 25$ refund processing fee. Details of local arrangements, registration, and accommodation are available from the workshop secretary, Melissa Dunivant, and at http://ibg.colorado.edu/ dokuwiki/doku.php?id=workshop:2017:start.

An outstanding international faculty roster includes:

Ben Neale (co-director), Cotton Seed, Tim Porteba. Broad Institute and MGH.

David Evans (co-director). Diamantina Institute, University of Queensland.
Manuel Ferreira, Nick Martin, Sarah Medland. Queensland Institute for Medical Research.

Stacey Cherny, Pak Sham. Genome Research Centre, University of Hong Kong.

Meike Bartels, Dorret Boomsma, Camelia Minica, Danielle Posthuma. Amsterdam Vrije Universiteit.

John Hewitt (Local Host), Luke Evans, Matt Keller, Jeff Lessem, Institute for Behavioral Genetics.

Jeff Barrett. Sanger Institute.

Lindon Eaves, Hermine Maes. Mike Neale, Brad Verhulst. Virginia Institute for Psychiatric and Behavioral Genetics.

Goncalo Abecasis, University of Michigan.

Further information may be obtained from John Hewitt, or the workshop coordinator, Melissa Dunivant, IBG, University of Colorado, Boulder, CO 80309-0447, USA; Telephone: 303-492-3405; Fax: 303-492-8063; email: John.Hewitt@Colorado.edu or Melissa.Dunivant@ Colorado.edu.

Individuals from underrepresented racial and ethnic groups, individuals with disabilities, and individuals from socially, culturally, economically, or educationally disadvantaged backgrounds are especially encouraged to attend. Partial financial support for US participants from these groups is available by application to the local host, John Hewitt.

Funding Financial support for this workshop is provided by Grant MH19918 from the National Institute of Mental Health. 